\title{
Effect of Change in Diameter on Muffler Transmission loss using COMSOL
}

\author{
P. B. Bhadke, K. A. Mahajan \\ (Department of Mechanical Engineering, M.E.S College of Engineering, S.P. Pune University, India)
}

\begin{abstract}
Muffler analysis is always challenging task due to complex design, shape and size limitation for specific application. In this paper the inlet diameter of muffler is varied for comparison. Two finite element methods (FEM) Results are compared using COMSOL 5.0 software. Two different muffler configurations are considered, representing the effects of adding absorptive lining and without absorptive lining to increase the transmission loss (TL), from computational analysis it is observed that for $40 \mathrm{~mm}$ inlet transmission loss is more compared with $30 \mathrm{~mm}$ inlet diameter.
\end{abstract}

Keywords - Transmission loss (TL), Acoustic liners,

\section{INTRODUCTION}

Mufflers are normally used to reduce exhaust noise of engine. The acoustical design of such muffler is challenging task for designer. The efficient design demand and its performance as per application forced engineers for development of various acoustic elements within muffler, like sudden change in area, rigid baffles, area discontinuities, different density absorptive liner and pipes with perforation and so on. However, sometimes these elements also lead to pressure drop in the flow. To overcome this drawback, absorptive liner with various combination of area discontinuities are used in muffler design. The TL behavior is analyzed by D. Denia et. al. [1] 2D axisymmetric analytical approach used for two-chamber muffler. Few effects were studied, including rigid baffle inside chamber, its radius \& position along axial direction with and extended inlet/outlet. S. Bilawchuk et. al. [2] The increased use of large industrial machinery and specific application silencer design, to minimize design time it would be helpful to have means to predict the TL characteristics before design. The prototype derivation based on mode matching techniques. For higher order modes R. Glav et. al. [3] presented for 2-port matrix for a folded resonator with neglecting flow interaction effects. The improved method solved Helmholtz's equation with FEM. Renato Barbieri et. al. [4] use shape design combine Zoutendijk's method and FEM. To control the pollution error quadratic triangular meshes are constructed and solved using Zoutendijk's feasible directions method, for constrained and unconstrained shape optimization studied. MinChie Chiu [5] worked on multi-chamber shape optimization without considering back pressure. Key Fonseca de Lima,[6-7] evaluated and validated appropriate size of inlet \& outlet duct by Parametric optimization. To study complex mufflers an Integrated TMM has developed \& validated up to the cut-off frequency comparisons with 3D FEM results, by changing internal configuration The TL characteristic can be altered. Xiang Yu et. al. [8] provided some guidelines for system optimization by studying effect of several configurations. Xiang Yu et. al. [9-12] presented a theoretical description of the overall TL for cascade-connected multiple sub-chambers to achieved desired attenuation performance. V. Ovidiu [10] considered two special cases of reactive silencer investigated acoustic performance using numerical and experimental techniques. Jin Woo Lee et. al. [11] Studied \& validated topology-optimization for a smaller volume of partition than the previous one

\subsection{Reactive Type Muffler}

\section{TYPES OF MUFFLERS}

It reduces the noise by using phenomena of destructive interference. Reflections occur when there is a change in geometry or an area discontinuity with the help of perforations in the pipes inside the muffler. Sound pulses are scatter out by offset inlet and outlet tube with perforations in all directions within muffler creates destructive interference. Sub-chambers and sudden changes in geometry they reduce noise at different frequencies due to that the exhaust gasses moved towards outlet, few configurations joined to create impedance mismatch.

\subsection{Absorptive Type Muffler}

Absorptive material converts Energy of sound waves into heat. It consists of perforated pipe within steel housing. Absorptive material lined in chamber which minimizes back pressure than reactive muffler. Absorptive mufflers create less back pressure than reactive mufflers. 


\section{THEROTICAL ANALYSIS OF MODEL}

Pressure acoustic used to solve this problem in frequency domain. The equation is a modified Helmholtz equation for the acoustic pressure $\mathrm{p}$

$$
\nabla \cdot\left(-\frac{\nabla p}{\rho}\right)-\frac{\omega^{2} p}{c^{2} \rho}=0
$$

Where $\omega$ is angular frequency, $\rho$ material density and $\mathrm{c}$ is the sound speed. In the absorbing glass wool, for Poroacoustics domain, $c_{c}=\omega / k c$, and a complex density, $\rho_{c}=k_{c} Z_{c} / \omega$, where $k_{c}$ is the wave number and $Z_{c}$ is the impedance. This is a so-called porous domain equivalent fluid model. For a highly porous material, Delany and Bazley equation parameters are used.

$$
\begin{aligned}
& k_{c}=k_{a}\left(1+0.098 \times\left(\frac{\rho_{a} f}{R_{f}}\right)^{-0.7}-i \times 0.189 \times\left(\frac{\rho_{a} f}{R_{f}}\right)^{-0.595}\right) \\
& Z_{c}=Z_{a}\left(1+0.057 \times\left(\frac{\rho_{a} f}{R_{f}}\right)^{0.374}-i \times 0.189 \times\left(\frac{\rho_{a} f}{R_{f}}\right)^{-0.732}\right)
\end{aligned}
$$

Where $R_{f}$ is the flow resistivity, and where $k_{a}=\omega / c_{a}$ and $Z_{a}=\rho_{a} c_{a}$. The attenuation is defined as the ratio between the incoming and outgoing acoustic energy.

$$
T L=10 \log \left(\frac{P_{\text {in }}}{P_{\text {out }}}\right)
$$

Here $P_{\text {in }}$ is incoming power at the inlet \& $P_{\text {out }}$ is the outgoing power at the outlet. Assuming plane wave propagation we can calculate TL as an integral over the respective inlet and outlet surface. The frequency above which all the frequencies are suppressed by the muffler is called cut-off frequency. This can achieve by using a Low \& High pass filter.

$$
P_{i n}=\int_{\partial \Omega} \frac{p_{0}^{2}}{2 \rho c} d A \text { and } P_{o u t}=\int_{\partial \Omega} \frac{|p|^{2}}{2 \rho c} d A
$$

\section{COMPUTATIONAL ANALYSIS \& STEPS INVOLVED}

\subsection{COMSOL Multiphysics Module}

This module contain many sub-module, we solve this problems in the Pressure acoustics module. The physics interfaces play a vital role to couple with other physics interface in COMSOL.

\subsection{Parameter Required for Simulation}

Table 1 List of Parameters required for simulation

\begin{tabular}{|l|l|l|}
\hline Name & Value & Description \\
\hline p0 & $1[\mathrm{~Pa}]$ & Amplitude of incoming pressure wave \\
\hline rho_ap & $12\left[\mathrm{~kg} / \mathrm{m}^{3}\right]$ & Apparent density of glass wool \\
\hline d_av & $10[\mathrm{um}]$ & Mean fiber diameter \\
\hline R_f & $1424.2 \mathrm{~kg} /\left(\mathrm{m}^{3} \cdot \mathrm{s}\right)$ & Flow resistivity \\
\hline
\end{tabular}

\subsection{Boundary Conditions}

Three boundary conditions are used to all problems.

- Hard wall boundary where velocity is zero.

- At the inlet combination of incoming and outgoing plane waves.

- At the outlet radiation condition for an outgoing plane wave. 


\subsection{Meshing the Model}

The wavelength $\lambda$ value depends on the sound speed and frequency $(\lambda=c / f)$. Meshing resolve this wavelength. Isotropic meshing used with twelve DOFs per wavelength.

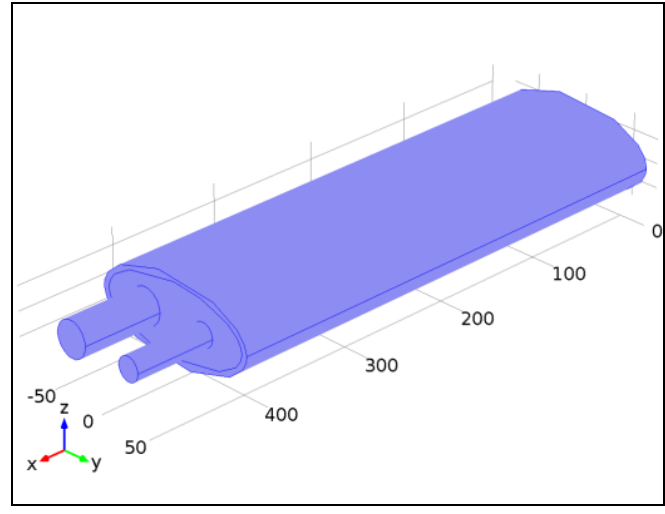

Fig. 2 a) without liner 30mm inlet

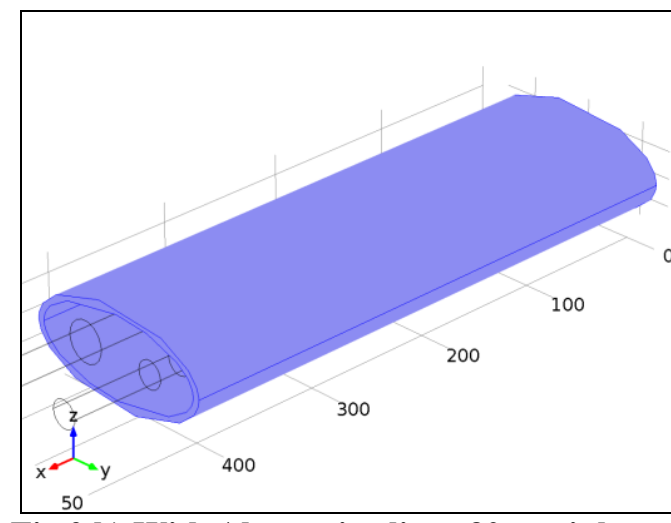

Fig.2 b) With Absorptive liner 30mm inlet

Fig. 2 a) shows complete muffler used for simulation with absorptive liner of Glass-wool and Fig. 2 b) shows only the Absorptive liner separately.

\subsection{Result of COMSOL 5.0}

The pressure distribution in the absorptive muffler with and without the lining material is shown in Fig.3 a) \& b) for the frequency $\mathrm{f}=600 \mathrm{~Hz}$. From the figure it is seen that at this frequency not only longitudinal standing waves exist. The behavior shows complicated and unpredictable damping properties for higher frequencies, while glass-wool improves TL at the resonance frequencies as well as at higher frequencies.

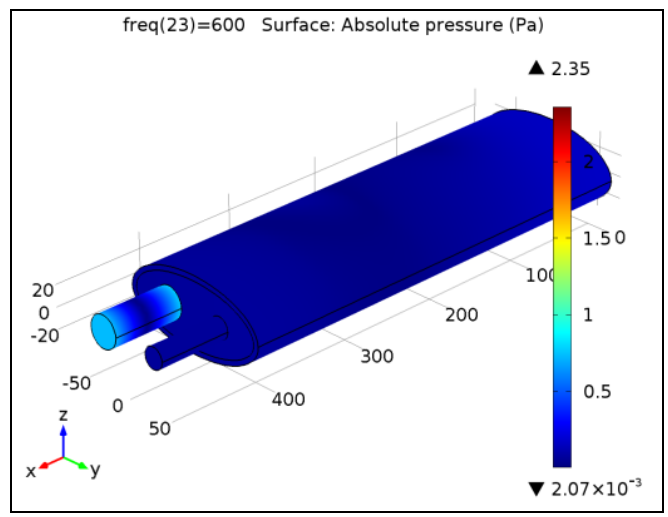

(a)

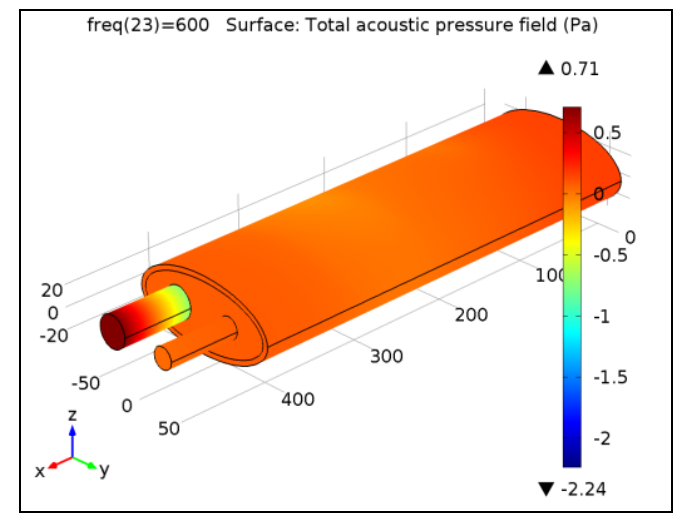

(b)

Fig. 3 Absolute pressure level a) without liner b) With Absorptive liner for 30mm inlet

Fig. 3 a) shows absolute pressure level of muffler at frequency of $600 \mathrm{~Hz}$ for $30 \mathrm{~mm}$ inlet pipe diameter. The absolute pressure value for $30 \mathrm{~mm}$ inlet without liner is $2.35 \mathrm{~Pa}$ while with Acoustic liner it is $0.71 \mathrm{~Pa}$.Fig. $4 \mathrm{a}$ ) shows sound pressure level of muffler at frequency of $600 \mathrm{~Hz}$ for $30 \mathrm{~mm}$ inlet pipe diameter, and it is same as we are giving constant sound pressure as input which is $1 \mathrm{~Pa}$. 


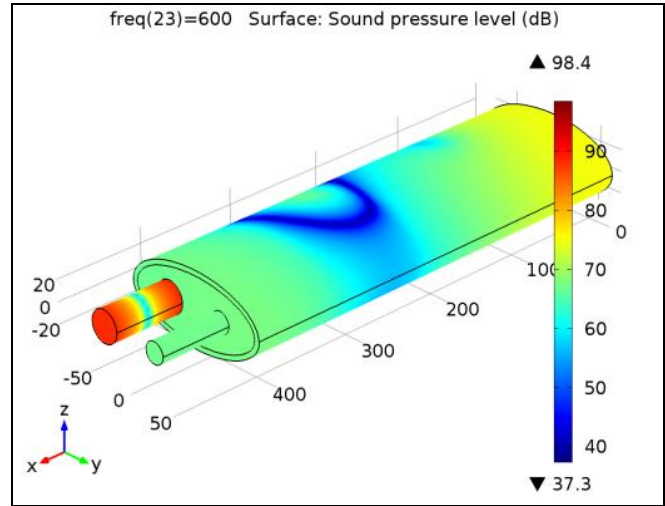

(a)

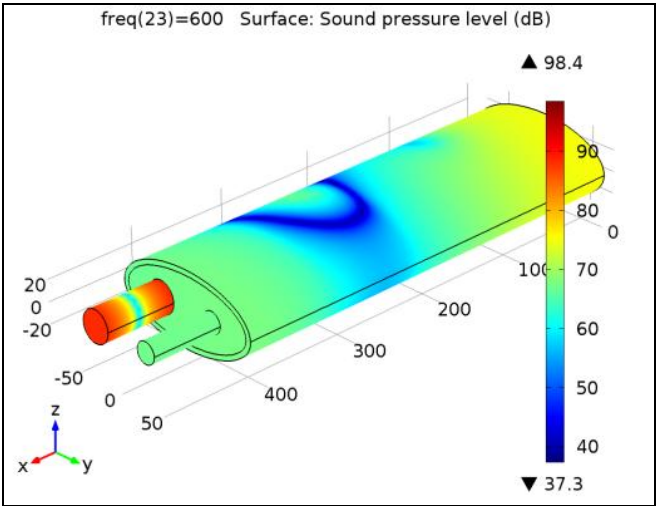

(b)

Fig. 4 Sound pressure level a) without liner b) With Absorptive liner 30mm inlet

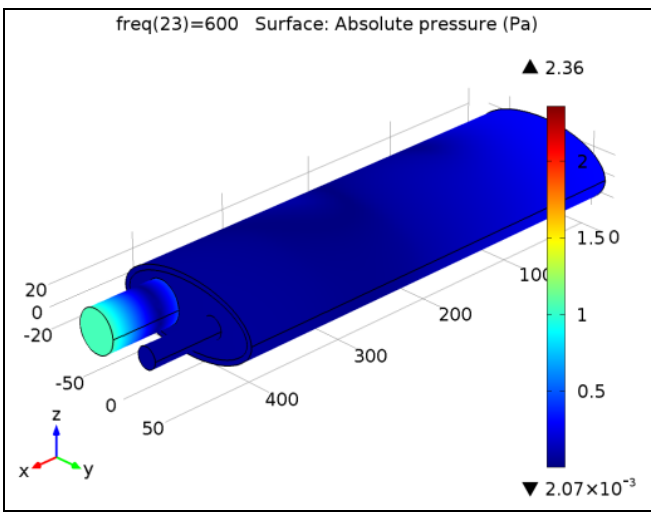

(a)

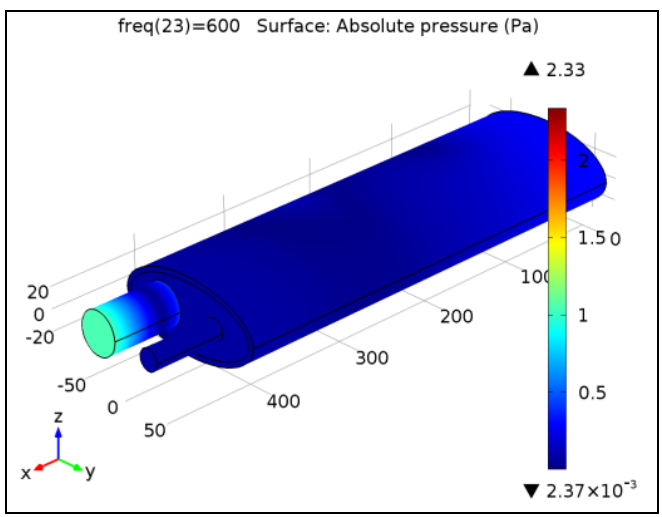

(b)

Fig. 5 Absolute pressure level a) without liner b) With Absorptive liner for $40 \mathrm{~mm}$ inlet

Fig. 5 a) shows absolute pressure level of muffler at frequency of $600 \mathrm{~Hz}$ for $40 \mathrm{~mm}$ inlet pipe diameter. The absolute pressure value for $40 \mathrm{~mm}$ inlet without liner is $2.35 \mathrm{~Pa}$ while with Acoustic liner it is 2.33Pa.

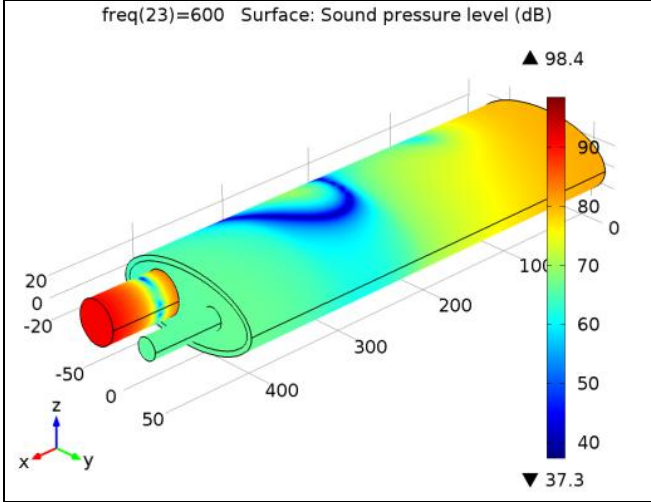

(a)

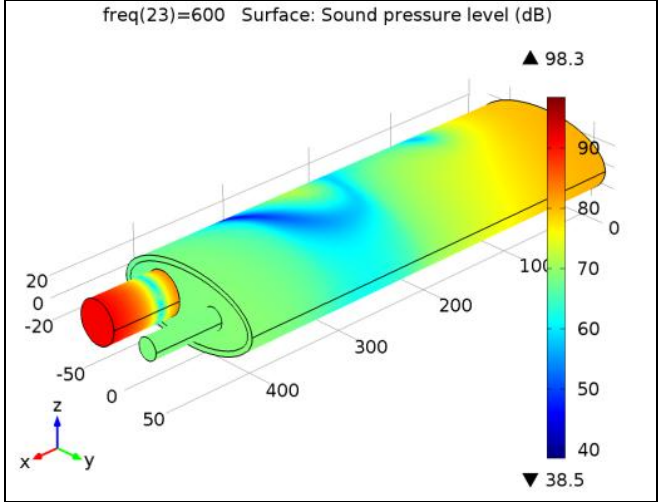

(b)

Fig. 6 Sound pressure level a) without liner b) With Absorptive liner 30mm inlet

Fig. 6 a) shows sound pressure level of muffler at frequency of $600 \mathrm{~Hz}$ for $30 \mathrm{~mm}$ inlet pipe diameter, and it is nearly same as we are giving constant sound pressure as input which is $1 \mathrm{~Pa}$. Fig. 7 a) shows plot of frequency $(\mathrm{Hz})$ vs. Transmission loss $(\mathrm{dB})$ of muffler for $30 \mathrm{~mm}$ inlet pipe diameter, maximum TL is $42 \mathrm{~dB}$ observed at $400 \mathrm{~Hz}$ frequency. b) Shows maximum TL is $52 \mathrm{~dB}$ observed at $450 \mathrm{~Hz}$ frequency. 


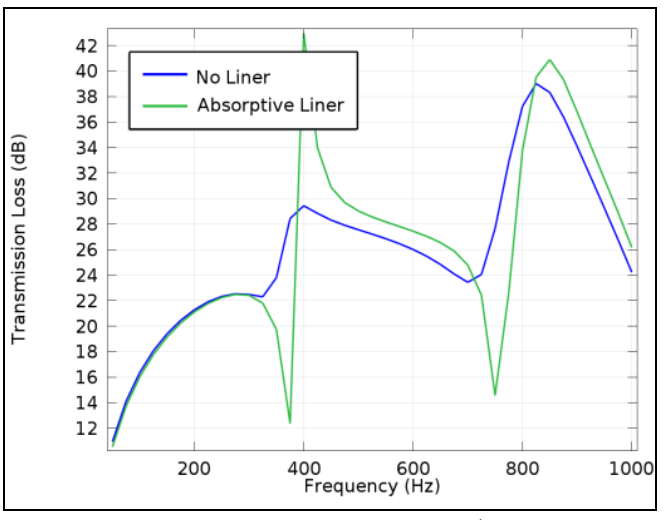

a)

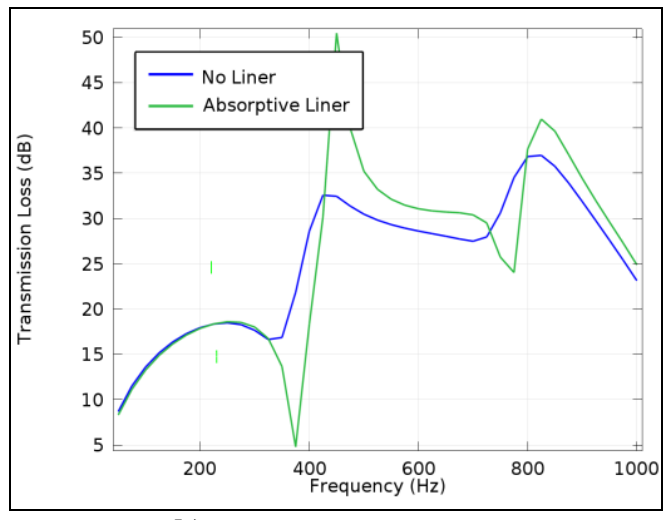

b)

Fig. 7 a) TL by COMSOL without liner and With Absorptive liner for 30mm inlet b) for 40mm inlet

\section{RESULTS AND DISCUSSION}

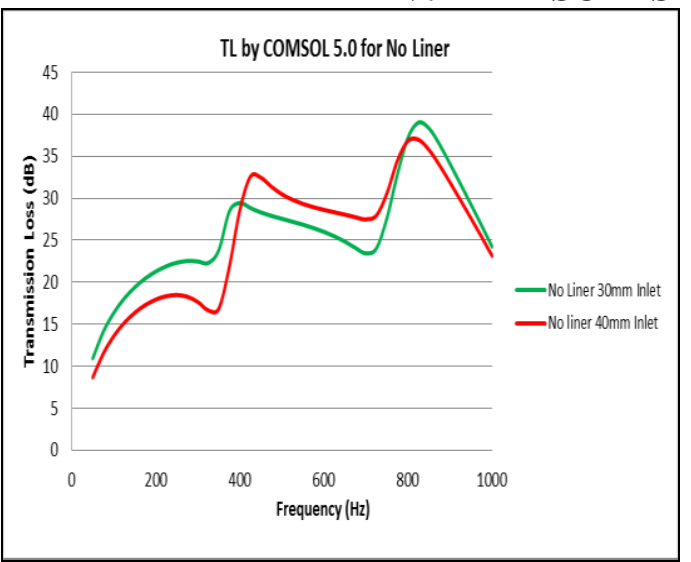

a)

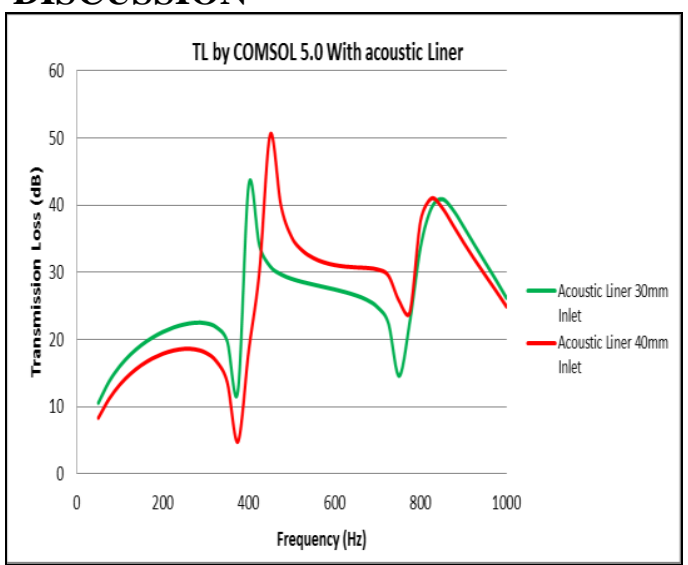

b)

Fig. 8 a) TL Comparison of COMSOL for 30 \& $40 \mathrm{~mm}$ inlet a) No liner b) With Acoustic liner

Fig. 8 shows graphs of transmission losses across a range of frequency. Fig 8 a) it is observed that on a frequency value of $800-850 \mathrm{~Hz}$ we get maximum attenuation of $39 \mathrm{~dB}$ for $30 \mathrm{~mm}$ inlet diameter and $36 \mathrm{~dB}$ for $40 \mathrm{~mm}$ inlet for without liner condition. Fig $8 \mathrm{~b}$ ) frequency value of $400-450 \mathrm{~Hz}$ we get maximum attenuation of $42 \mathrm{~dB}$ for $30 \mathrm{~mm}$ inlet diameter and $50 \mathrm{~dB}$ for $40 \mathrm{~mm}$ inlet for with Acoustic liner condition. We can clearly see that for larger diameter of inlet manifold we get maximum transmission loss.

\section{CONCLUSION}

Fig. 7 a) is FEM output of muffler for $30 \mathrm{~mm}$ inlet diameter and fig. $7 \mathrm{~b}$ ) is FEM output of muffler for $40 \mathrm{~mm}$ inlet diameter. In fig. 8 a) is TL plot without absorptive liner for $30 \mathrm{~mm}$ (Green line) inlet and $40 \mathrm{~mm}$ inlet(Red Line) for this condition TL is more for $40 \mathrm{~mm}$ inlet. In fig. $8 \mathrm{~b}$ ) is TL plot with absorptive liner for $30 \mathrm{~mm}$ (Green line) inlet and 40mm inlet(Red Line) for this condition TL is more for 40mm inlet. We can also conclude that if we increase the diameter of inlet manifold we get increased transmission loss.

\section{REFERENCES}

[1] S. Bilawchuk and K. R. Fyfe, Comparison and implementation of the various numerical methods used for calculating transmission loss in silencer systems, Applied Acoustics, 64, 2003, 903-916.

[2] R. Glav, P.-L. Regaud, and M. Åbom, Study of a folded resonator including the effects of higher order modes, Journal of Sound and Vibration, 273, (4-5), 2004, 777-792.

[3] R. Barbieri and N. Barbieri, Finite element acoustic simulation based shape optimization of a muffler, Applied Acoustics, 67(4), April 2006, 346-357.

[4] M.-C. Chiu, Shape optimization of multi-chamber mufflers with plug-inlet tube on a venting process by genetic algorithms,Applied Acoustics, 71, 2010, 495-505.

[5] K. Fonseca De Lima, A. Lenzi, and R. Barbieri, The study of reactive silencers by shape and parametric optimization techniques,Applied Acoustics, 72, 2011, 142-150.

[6] N. K. Vijayasree and M. L. Munjal, On an Integrated Transfer Matrix method for multiply connected mufflers, Journal of Sound and Vibration, 331(8), 2012 1926-1938. 
[7] Y. Yao, S. Wei, J. Zhao, S. Chen, Z. Feng, and J. Yue, Experiment and CFD Analysis of Reactive Muffler,Journal of Applied Science and Engineering Technology, 6(17), 2013,3282-3288.

[8] X. Yu and L. Cheng, Duct noise attenuation using reactive silencer with various internal configurations,Journal of Sound and Vibration, 335, $2014,229-244$.

[9] V. Ovidiu, Theoretical and Experimental Analysis of Acoustic Performances on The Multi, International Congress on Sound and Vibration ,2014, 13-17.

[10] J. W. Lee, Optimal topology of reactive muffler achieving target transmission loss values: Design and experiment,Applied Acoustics 2015.

[11] Selamet, F. D. Denia, and a. J. Besa, Acoustic behavior of circular dual-chamber mufflers,Journal of Sound and Vibration. 265(5), 2003, 967-985.

[12] X. Yu, Y. Tong, J. Pan, and L. Cheng, Sub-chamber optimization for silencer design, Journal of Sound and Vibration. 351, 2015 57-67.

[13] M.A.Delany and E.N. Bazley, Acoustic Properties of Fibrous Absorbent Materials, Applied Acoustics, 03(4), 1970,105-116.

[14] D.A. Bies and C.H. Hansen, Flow Resistance Information for Acoustical Design,Applied Acoustics 13(5), 1970, 357391.

[15] M. L. Munjal.,Acoustic of Ducts and muffler, (Wiley, New York 1987). 